\title{
Bench Evaluation of 7 Home-Care Ventilators
}

\author{
Thomas C Blakeman MSc RRT, Dario Rodriquez Jr RRT, Dennis Hanseman PhD, and \\ Richard D Branson MSc RRT FAARC
}

\begin{abstract}
BACKGROUND: Portable ventilators continue to decrease in size while increasing in performance. We bench-tested the triggering, battery duration, and tidal volume $\left(V_{T}\right)$ of 7 portable ventilators: LTV 1000, LTV 1200, Puritan Bennett 540, Trilogy, Vela, iVent 101, and HT50. METHODS: We tested triggering with a modified dual-chamber test lung to simulate spontaneous breathing with weak, normal, and strong inspiratory effort. We measured battery duration by fully charging the battery and operating the ventilator with a $V_{T}$ of $500 \mathrm{~mL}$, a respiratory rate of 20 breaths $/ \mathrm{min}$, and PEEP of $5 \mathrm{~cm} \mathrm{H}_{2} \mathrm{O}$ until breath-delivery ceased. We tested $\mathrm{V}_{\mathrm{T}}$ accuracy with pediatric ventilation scenarios $\left(V_{T} 50 \mathrm{~mL}\right.$ or $100 \mathrm{~mL}$, respiratory rate 50 breaths/min, inspiratory time $0.3 \mathrm{~s}$, and PEEP $\left.5 \mathrm{~cm} \mathrm{H}_{2} \mathrm{O}\right)$ and an adult ventilation scenario $\left(\mathrm{V}_{\mathrm{T}} 400 \mathrm{~mL}\right.$, respiratory rate 30 breaths $/ \mathrm{min}$, inspiratory time $0.5 \mathrm{~s}$, and PEEP $5 \mathrm{~cm} \mathrm{\textrm {H } _ { 2 }} \mathrm{O}$ ). We measured and analyzed airway pressure, volume, and flow signals. RESULTS: At the adult settings the measured $V_{T}$ range was $362-426 \mathrm{~mL}$. On the pediatric settings the measured $V_{T}$ range was $51-182 \mathrm{~mL}$ at the set $V_{T}$ of $50 \mathrm{~mL}$, and $90-141 \mathrm{~mL}$ at the set $V_{T}$ of $100 \mathrm{~mL}$. The $V_{T}$ delivered by the Vela at both the $50 \mathrm{~mL}$ and $100 \mathrm{~mL}$, and by the HT50 at $100 \mathrm{~mL}$, did not meet the American Society for Testing and Materials standard for $V_{T}$ accuracy. Triggering response and battery duration ranged widely among the tested ventilators. CONCLUSIONS: There was wide variability in battery duration and triggering sensitivity. Five of the ventilators performed adequately in $V_{T}$ delivery across several settings. The combination of high respiratory rate and low $\mathbf{V}_{\mathrm{T}}$ presented problems for $\mathbf{2}$ of the ventilators. Key words: mechanical ventilation; portable ventilator; home care; triggering; battery duration. [Respir Care 2011;56(11): 1791-1798. (c) 2011 Daedalus Enterprises]
\end{abstract}

\section{Introduction}

Advances in medical care have prolonged patients' lives, at the cost of prolonged physical and pulmonary rehabilitation, often associated with ventilator dependence. ${ }^{1,2}$ During the past 2 decades there has also been an increase in

\footnotetext{
Mr Blakeman, Dr Hanseman, and Mr Branson are affiliated with the Department of Surgery, Division of Trauma and Critical Care; and Mr Rodriquez is affiliated with the United States Air Force Center for Sustainment of Trauma and Readiness Skills, University of Cincinnati Medical Center, Cincinnati, Ohio.
}

Mr Blakeman presented a version of this paper at the 56th International Respiratory Congress of the American Association for Respiratory Care, held December 6-9, 2010, in Las Vegas, Nevada.

The authors have disclosed a relationship with GE Healthcare. Mr Branson has disclosed relationships with Ikaria, CareFusion, Covidien, and Advanced Circulatory Systems. the number of patients with chronic respiratory failure who require home mechanical ventilation. With the increasing cost of healthcare and the advancement of technology, there is impetus to move ventilator-dependent patients from acute, subacute, and long-term care facilities to home. Ventilators intended for home use often have many of the desirable features of intensive care unit (ICU) ventilators and provide greater comfort and ease of interaction. ${ }^{3}$ We bench tested the triggering, battery duration, and tidal volume $\left(\mathrm{V}_{\mathrm{T}}\right)$ of 7 ventilators intended for long-term home use.

\footnotetext{
Correspondence: Thomas C Blakeman RRT, Division of Trauma and Critical Care, Department of Surgery, University of Cincinnati Medical Center, 231 Albert Sabin Way, ML 0558, Cincinnati OH 45267-0558. E-mail: thomas.blakeman@uc.edu.
}

DOI: $10.4187 /$ respcare. 01176 
Bench Evaluation of 7 Home-Care Ventilators

Table 1. Tested Ventilators*

\begin{tabular}{|c|c|c|c|c|c|c|}
\hline Model & Manufacturer & $\begin{array}{l}\text { Dimensions } \\
(\mathrm{cm})\end{array}$ & $\begin{array}{l}\text { Weight } \\
(\mathrm{kg})\end{array}$ & Flow Driver & $\mathrm{V}_{\mathrm{T}}$ Monitoring & $\begin{array}{l}\text { Internal Battery } \\
\text { Type }\end{array}$ \\
\hline LTV 1000 & $\begin{array}{l}\text { CareFusion, San Diego, } \\
\text { California }\end{array}$ & $30 \times 25 \times 8$ & 6.1 & Turbine & Inspired and expired & Lead/acid \\
\hline LTV 1200 & $\begin{array}{l}\text { CareFusion, San Diego, } \\
\text { California }\end{array}$ & $30 \times 25 \times 8$ & 6.1 & Turbine & Inspired and expired & Lead/acid \\
\hline $\begin{array}{l}\text { Puritan Bennett } \\
\quad 540\end{array}$ & $\begin{array}{l}\text { Nellcor Puritan Bennett, } \\
\text { Carlsbad, California }\end{array}$ & $31 \times 24 \times 15$ & 4.5 & Turbine & $\begin{array}{l}\text { Inspired and expired, } \\
\text { with dual-limb } \\
\text { circuit }\end{array}$ & Lithium ion \\
\hline Trilogy & $\begin{array}{l}\text { Philips Respironics, Murrysville, } \\
\text { Pennsylvania }\end{array}$ & $17 \times 28 \times 24$ & 5.0 & Turbine & Inspired only & Lithium ion \\
\hline Vela & $\begin{array}{l}\text { CareFusion, San Diego, } \\
\text { California }\end{array}$ & $37 \times 33 \times 30$ & 17.2 & Turbine & Inspired and expired & Nickel/metal hydride \\
\hline iVent 101 & $\begin{array}{l}\text { GE Healthcare, Madison, } \\
\text { Wisconsin }\end{array}$ & $25 \times 25 \times 19$ & 6.1 & Turbine & $\begin{array}{l}\text { Inspired and expired, } \\
\text { with dual-limb } \\
\text { circuit }\end{array}$ & Nickel/metal hydride \\
\hline HT50 & $\begin{array}{l}\text { Newport Medical, Newport } \\
\text { Beach, California }\end{array}$ & $20 \times 28 \times 25$ & 6.8 & Micro Pistons & Inspired only & Lead/acid \\
\hline
\end{tabular}

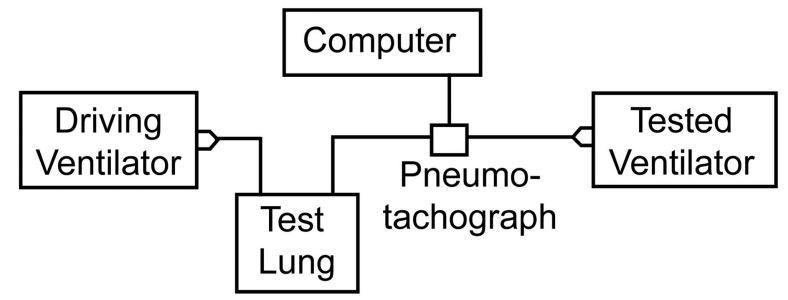

Fig. 1. Experiment setup.

\section{Methods}

\section{Ventilators}

We tested 7 ventilators (Table 1). We used the Evita XL as the control ventilator because the majority of ICU ventilators at our facility are Evita XLs. All the ventilators were set up, and operational verification tests were performed, per the manufacturer's instructions. The ventilator circuit that was intended to provide invasive ventilation was supplied by the manufacturer. In all the tests, each ventilator was attached to one chamber of a dual-chamber test lung (Training and Test Lung, Michigan Instruments, Grand Rapids, Michigan). A second ventilator was attached to the test lung's driving chamber with a metal lift bar between the chambers, to simulate a patient-triggered breath (Fig. 1). ${ }^{4}$

\section{Triggering}

We evaluated triggering with a pressure-differential pneumotachometer (Cosmo, Philips Respironics, Andover,
Massachusetts) between the ventilator and test lung. We recorded pressure measurements during each ventilator breath. We evaluated triggering response at inspiratory flow/ $/ \mathrm{V}_{\mathrm{T}}$ combinations of $20 \mathrm{~L} / \mathrm{min}$ and $100 \mathrm{~mL}, 40 \mathrm{~L} / \mathrm{min}$ and $300 \mathrm{~mL}$, and $80 \mathrm{~L} / \mathrm{min}$ and $600 \mathrm{~mL}$ in volume control continuous mandatory ventilation mode, to represent weak, normal, and strong inspiratory efforts, respectively. All the flow/volume combinations were tested at PEEP of $5 \mathrm{~cm} \mathrm{H}_{2} \mathrm{O}$ and pressure support (PS) of 0 and $20 \mathrm{~cm} \mathrm{H}_{2} \mathrm{O}$ above PEEP. We constructed pressure waveforms from the recorded data. After a 1-minute stabilization period we recorded data from 3 breaths. We analyzed the breath that produced the lowest negative pressure change and the subsequent 2 breaths. We evaluated triggering performance with 3 criteria:

- The lowest negative pressure generated during a simulated inspiratory effort. A lower value indicates a lower inspiratory effort required to trigger the ventilator.

- Time delay, defined as the time during which airway pressure remained below baseline. The time delay is dependent on the triggering and pressurizing responses.

- Rise time, defined as the time from baseline after triggering to $90 \%$ of the set PS level. The rise time is an indication of the ventilator's ability to recover from the negative-pressure phase of triggering and to activate gas delivery.

With all the ventilators we used the fastest rise time that did not result in overshoot, and the lowest triggering sensitivity that did not produce auto-triggering. 


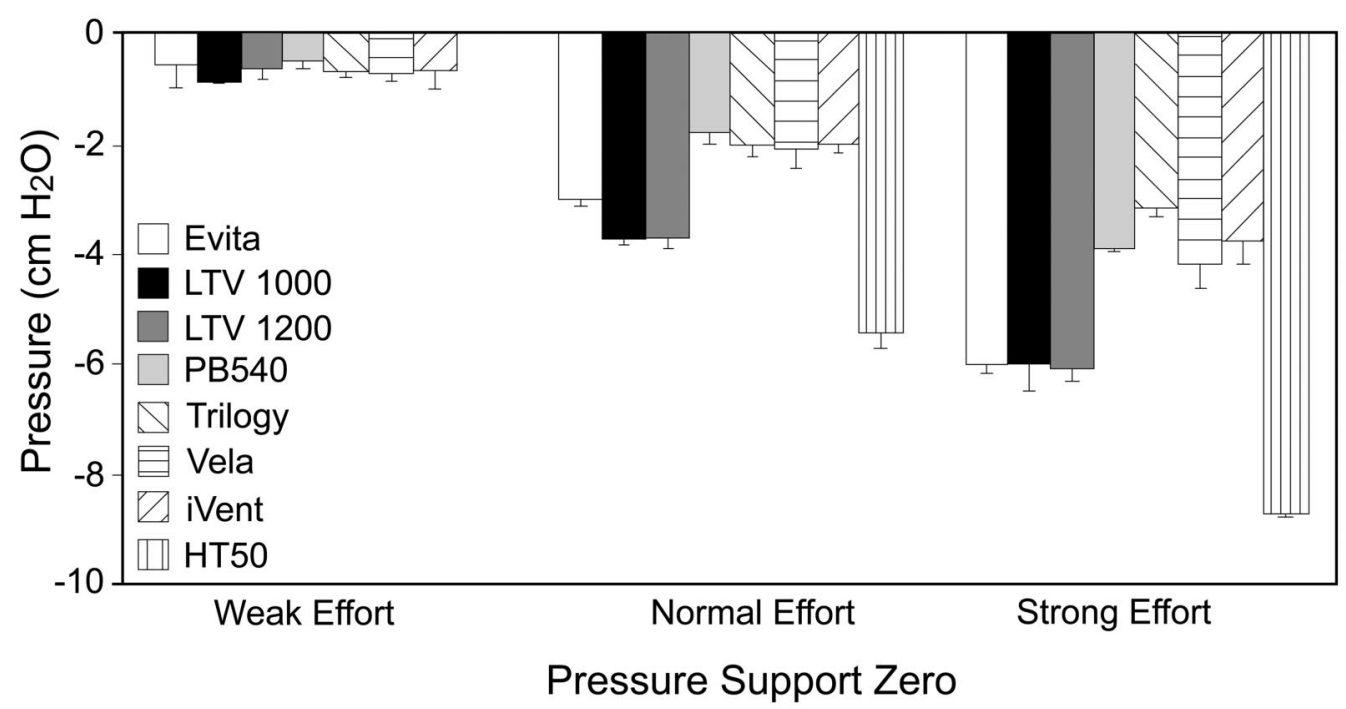

Fig. 2. Lowest negative pressure generated with zero pressure support. The HT50 failed to trigger with the weak inspiratory effort.

\section{Tidal Volume}

We measured the delivered $\mathrm{V}_{\mathrm{T}}$ with a pneumotachograph (PF-301 FlowAnalyser, IMT Medical, Buchs, Switzerland) placed between the ventilator and the test lung. Each ventilator was tested in volume control mode, in 3 ventilation scenarios:

- Set $\mathrm{V}_{\mathrm{T}} 50 \mathrm{~mL}$, respiratory rate 50 breaths $/ \mathrm{min}$, inspiratory time 0.3 second, set compliance $0.025 \mathrm{~L} / \mathrm{cm} \mathrm{H}_{2} \mathrm{O}$, set resistance $20 \mathrm{~cm} \mathrm{H}_{2} \mathrm{O} / \mathrm{L} / \mathrm{s}$

- Set $\mathrm{V}_{\mathrm{T}} 100 \mathrm{~mL}$, respiratory rate 50 breaths/min, inspiratory time 0.3 second, set compliance $0.025 \mathrm{~L} / \mathrm{cm} \mathrm{H}_{2} \mathrm{O}$, set resistance $20 \mathrm{~cm} \mathrm{H}_{2} \mathrm{O} / \mathrm{L} / \mathrm{s}$

- Set $\mathrm{V}_{\mathrm{T}} 400 \mathrm{~mL}$, respiratory rate 30 breaths $/ \mathrm{min}$, inspiratory time 0.5 second, set compliance $0.05 \mathrm{~L} / \mathrm{cm} \mathrm{H}_{2} \mathrm{O}$, set resistance $10 \mathrm{~cm} \mathrm{H}_{2} \mathrm{O} / \mathrm{L} / \mathrm{s}$

All the tests were with no supplemental oxygen $\left(\mathrm{F}_{\mathrm{IO}_{2}}\right.$ 0.21 ). In each scenario, after a 1-minute stabilization period, the ventilator was operated for 1 minute. We averaged the data from 50 breaths in the $\mathrm{V}_{\mathrm{T}} 50 \mathrm{~mL}$ and $\mathrm{V}_{\mathrm{T}} 100 \mathrm{~mL}$ scenarios, and from 30 breaths in the $\mathrm{V}_{\mathrm{T}} 400 \mathrm{~mL}$ scenario.

\section{Battery Duration}

We evaluated battery duration in volume control continuous mandatory ventilation mode, with a respiratory rate of 20 breaths $/ \mathrm{min}, \mathrm{V}_{\mathrm{T}}$ of $500 \mathrm{~mL}$, PEEP of $5 \mathrm{~cm} \mathrm{H}_{2} \mathrm{O}$, compliance of $0.05 \mathrm{~L} / \mathrm{cm} \mathrm{H}_{2} \mathrm{O}$, and resistance of $5 \mathrm{~cm} \mathrm{H}_{2} \mathrm{O}$ / $\mathrm{L} / \mathrm{s}$. We tested the manufacturer-supplied integrated internal battery. Each ventilator was equipped with a new battery that had been charged for 24 hours prior to testing, and operated on battery power to exhaustion. We conducted one battery test per ventilator. The ventilator was attached to the test lung and we continuously recorded pressure, volume, and flow (RSS 100, Hans-Rudolph, Shawnee, Kansas).

We used nonparametric methods to analyze the differences between the tested ventilators and the control ventilator (Evita XL). Analysis began with a nonparametric Kruskal-Wallis test (SAS 9.2, SAS Institute, Cary, North Carolina) for between-ventilator differences. If a difference was significant $(P<.05)$, that was evidence of at least one difference between a test ventilator and the control, and we tested pair-wise differences to control for the fact that multiple hypotheses tests were undertaken on the same data set. Any difference with an adjusted $P<.05$ was deemed significant.

\section{Results}

\section{Triggering}

The triggering evaluation constituted a substantial portion of the testing. Figures 2 and 3 show the lowest negative pressure generated from baseline at PS of zero and $20 \mathrm{~cm} \mathrm{H}_{2} \mathrm{O}$. At both PS settings, the lowest negative pressure was greatest with the strong inspiratory effort, and least with the weak effort, across all ventilators (range -0.47 to $-0.88 \mathrm{~cm} \mathrm{H}_{2} \mathrm{O}$ ). There were no significant differences between the test ventilators and the control ventilator. The HT50 generated the lowest negative pressure $\left(-8.7 \mathrm{~cm} \mathrm{H}_{2} \mathrm{O}\right)$ at both PS settings, with the strong effort. At each inspiratory effort level, the lowest negative pressure with each ventilator was similar at both PS settings. The HT50 consistently produced the lowest negative pres- 


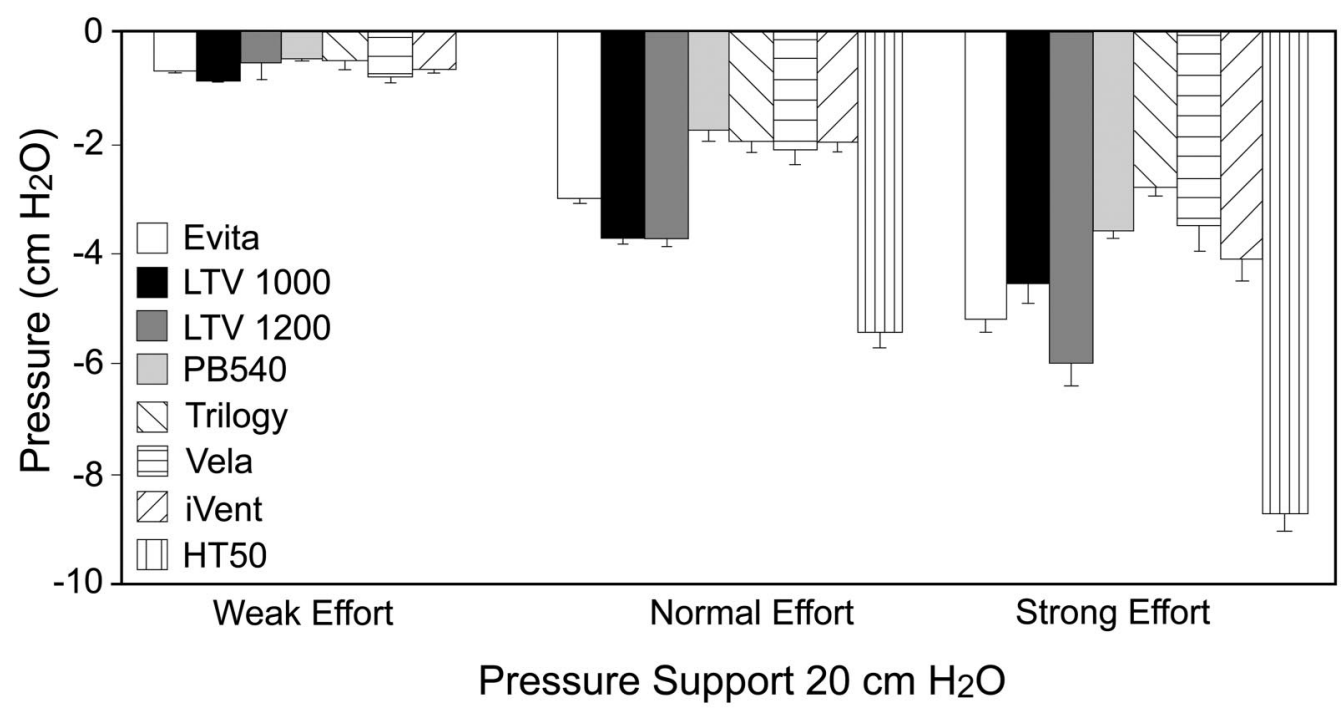

Fig. 3. Lowest negative pressure generated with pressure support of $20 \mathrm{~cm} \mathrm{H}_{2} \mathrm{O}$. The HT50 failed to trigger with the weak inspiratory effort.

sure and longest delay time, regardless of effort or PS setting, which was significantly inferior to the Evita XL. However, the HT50 failed to trigger with a simulated weak effort at either PS setting. Decreasing the sensitivity setting enabled the HT50 more easily to respond to the negative-pressure-caused auto-triggering, whereas setting the HT50 less sensitive would not allow triggering. We opted for the less sensitive setting that did not allow auto-triggering.

At both 0 PS and PS of $20 \mathrm{~cm} \mathrm{H}_{2} \mathrm{O}$, the Puritan Bennett 540, Trilogy, Vela, and iVent were significantly superior to the Evita XL in the lowest-negative-pressure test. The LTV 1000 and LTV 1200 were not significantly different from the Evita XL.

At 0 PS the LTV 1000, LTV 1200, Vela, and iVent were significantly superior to the Evita XL in the delay-time test with the strong effort. There was no significant difference between the Puritan Bennett 540 or Trilogy and the Evita XL. With a normal effort and 0 pressure support there were no significant delay-time differences between the tested ventilators and the control ventilator. The risetime evaluation was not done at 0 pressure support.

At 0 PS of $20 \mathrm{~cm} \mathrm{H}_{2} \mathrm{O}$ the only significant delay-time difference was with the HT50. The LTV 1200, Puritan Bennett 540, Vela, and iVent were significantly inferior to the Evita XL in the rise-time test, whereas the LTV 1000 was significantly superior. There was no significant difference with the Trilogy or Evita XL.

Figures 4 and 5 show the trigger-delay results. The delay-time range was $107-610 \mathrm{~ms}$ with 0 pressure support, and $127-313 \mathrm{~ms}$ with pressure support of $20 \mathrm{~cm} \mathrm{H}_{2} \mathrm{O}$. The longest delay time was with the HT50, which failed to trigger with the weak inspiratory effort.
Figure 6 shows the rise-time results. The shortest rise time (237 ms) was with the LTV 1000, and the longest (610 ms) was with the Puritan Bennett 540. The LTV 1200, Trilogy, Vela, and iVent 101 had similar rise times (mean rise time $485 \pm 12 \mathrm{~ms}$ ), and their rise times were inferior to the Evita XL. The HT50 and LTV 1000 rise times (237 ms and $330 \mathrm{~ms}$, respectively) were superior to the Evita XL (390 ms).

\section{Tidal Volume}

$\mathrm{V}_{\mathrm{T}}$ significantly differed among the ventilators. The $\mathrm{V}_{\mathrm{T}}$ difference increased with $\mathrm{V}_{\mathrm{T}}$ of 100 and $\mathrm{V}_{\mathrm{T}}$ of $50 \mathrm{~mL}$ at a respiratory rate of 50 breaths $/ \mathrm{min}$. At a set $\mathrm{V}_{\mathrm{T}}$ of $400 \mathrm{~mL}$ the delivered $\mathrm{V}_{\mathrm{T}}$ range was $362-426 \mathrm{~mL}$ among all the ventilators, which is within the $\pm 10 \%$ standard of the American Society for Testing and Materials. At a set $\mathrm{V}_{\mathrm{T}}$ of $100 \mathrm{~mL}$ the delivered $\mathrm{V}_{\mathrm{T}}$ range was $90-141 \mathrm{~mL}$. The HT50 and the Vela had the largest differences in delivered $\mathrm{V}_{\mathrm{T}}: 141 \mathrm{~mL}$ and $128 \mathrm{~mL}$, respectively. At a set $\mathrm{V}_{\mathrm{T}}$ of $50 \mathrm{~mL}$ the delivered $\mathrm{V}_{\mathrm{T}}$ range was $51-182 \mathrm{~mL}$. The Vela had the largest variability in delivered $\mathrm{V}_{\mathrm{T}}: 182 \mathrm{~mL}$. The ability to adjust inspiratory pressure in pressure control mode enabled us to achieve a delivered $\mathrm{V}_{\mathrm{T}}$ within $10 \%$ of the target $\mathrm{V}_{\mathrm{T}}$ of $100 \mathrm{~mL}$ and $400 \mathrm{~mL}$. At the $50 \mathrm{~mL}$ target $\mathrm{V}_{\mathrm{T}}$ there remained considerable differences between the ventilators (Table 2).

\section{Battery Duration}

Battery duration ranged widely (Fig. 7). The LTV 1200 had the shortest battery duration (108 min), and the HT50 had the longest (561 min). 


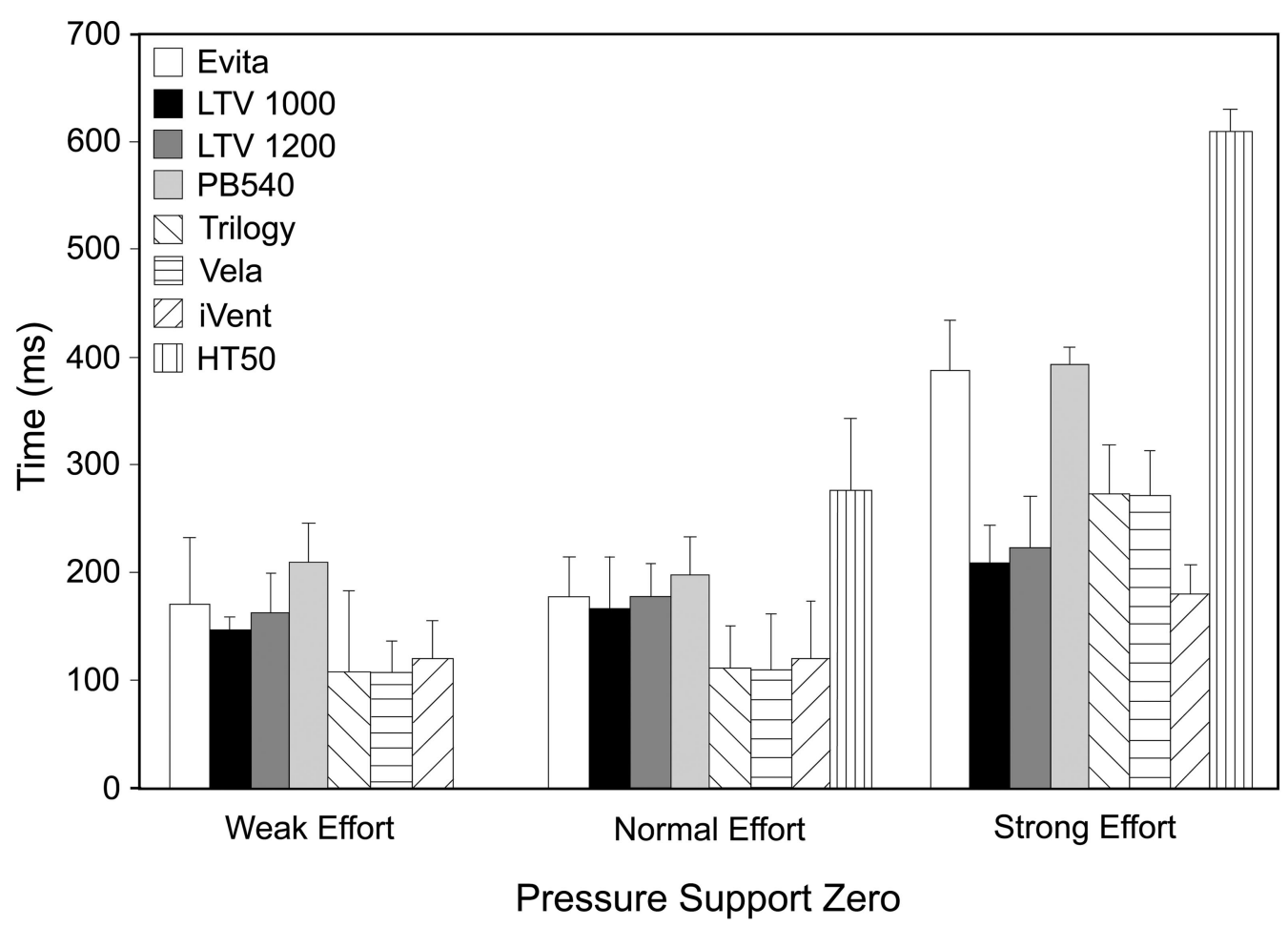

Fig. 4. Trigger delay with zero pressure support. The HT50 failed to trigger with the weak inspiratory effort.

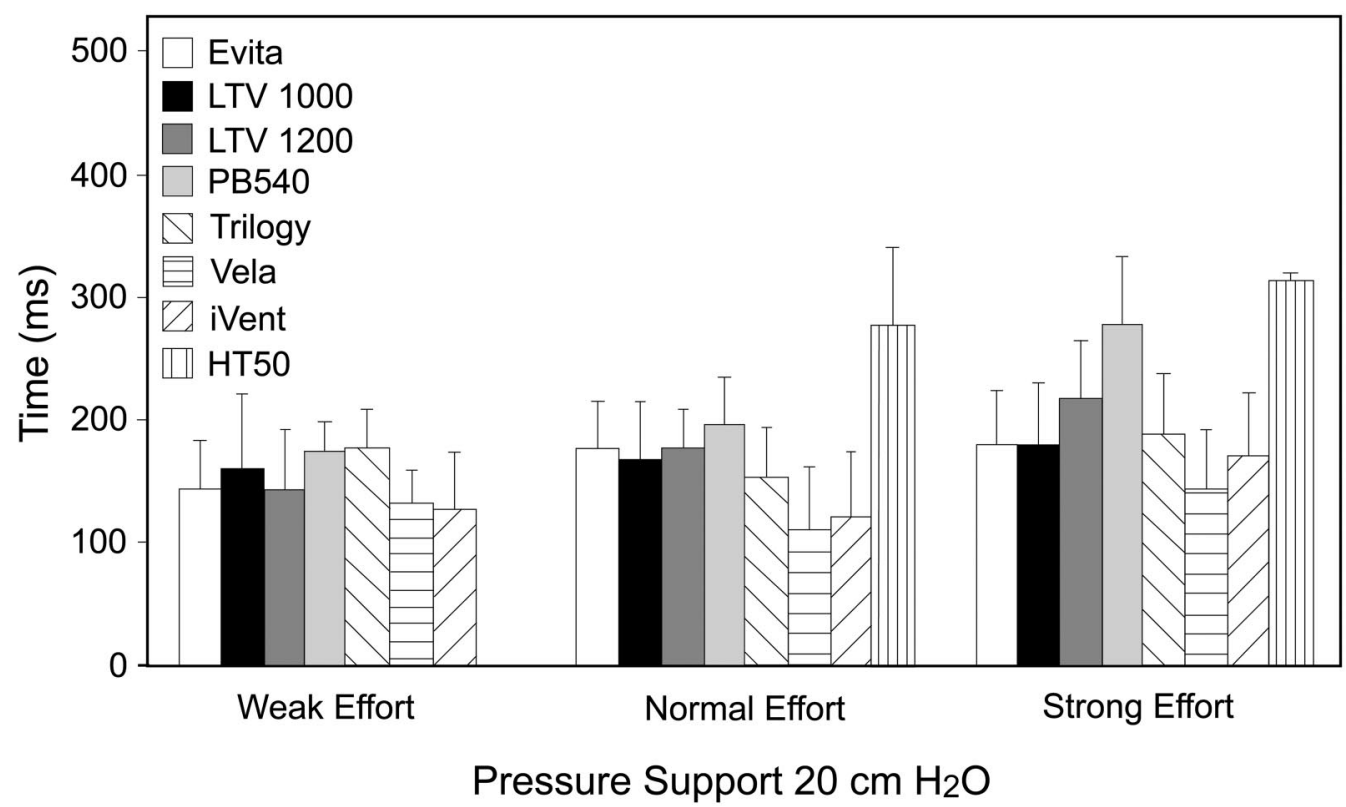

Fig. 5. Trigger delay with pressure support of $20 \mathrm{~cm} \mathrm{H}_{2} \mathrm{O}$. The HT50 failed to trigger with the weak inspiratory effort.

\section{Discussion}

Our results agree with the findings of Ferreira et $\mathrm{al}^{5}$; this suggests that, although differences remain, the performance of subacute and home-care ventilators has improved, and in some variables they are on par with or superior to ICU ventilators. While our data are similar, we did not use the same model or simulate comparable flow or $\mathrm{V}_{\mathrm{T}}$ settings. This explains the difference in absolute results but similarity in ranking of ventilators. 


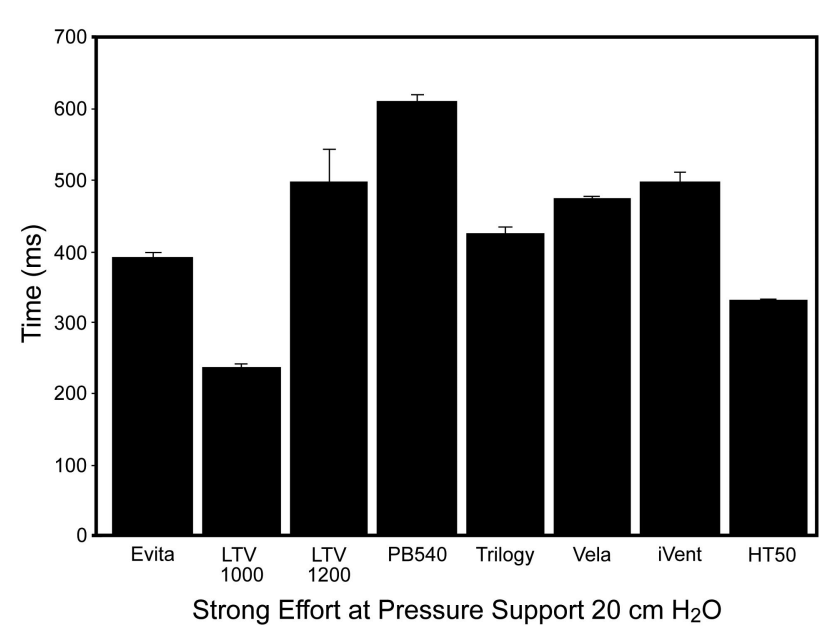

Fig. 6. Rise time with pressure support of $20 \mathrm{~cm} \mathrm{H}_{2} \mathrm{O}$ and strong inspiratory effort.

Table 2. Set Versus Delivered $\mathrm{V}_{\mathrm{T}}$ in Volume Control Mode

\begin{tabular}{|c|c|c|c|}
\hline & \multicolumn{3}{|c|}{ Set $\mathrm{V}_{\mathrm{T}}$ and Respiratory Rate } \\
\hline & $\begin{array}{c}V_{\mathrm{T}} 50 \mathrm{~mL} \\
\text { f } 50 \text { breaths } / \mathrm{min}\end{array}$ & $\begin{array}{c}\mathrm{V}_{\mathrm{T}} 100 \mathrm{~mL} \\
\text { f } 50 \text { breaths } / \mathrm{min}\end{array}$ & $\begin{array}{c}\mathrm{V}_{\mathrm{T}} 400 \mathrm{~mL} \\
\text { f } 30 \text { breaths } / \mathrm{min}\end{array}$ \\
\hline Evita XL & $56 \pm 0$ & $91 \pm 1$ & $362 \pm 1$ \\
\hline LTV 1000 & $56 \pm 1$ & $100 \pm 1$ & $387 \pm 1$ \\
\hline LTV 1200 & $57 \pm 0$ & $103 \pm 1$ & $390 \pm 1$ \\
\hline $\begin{array}{l}\text { Puritan Bennett } \\
\quad 540\end{array}$ & $64 \pm 2$ & $110 \pm 2$ & $426 \pm 2$ \\
\hline Trilogy & $51 \pm 7$ & $90 \pm 1$ & $362 \pm 1$ \\
\hline Vela & $182 \pm 3$ & $128 \pm 40$ & $387 \pm 0$ \\
\hline iVent 101 & $57 \pm 1$ & $112 \pm 1$ & $420 \pm 4$ \\
\hline HT50 & NA & $141 \pm 9$ & $424 \pm 16$ \\
\hline \multicolumn{4}{|c|}{$\begin{array}{l}\mathrm{f}=\text { frequency (respiratory rate) } \\
\mathrm{NA}=\text { not applicable: } 50 \mathrm{~mL} \text { tidal volume }\left(\mathrm{V}_{\mathrm{T}}\right) \text { setting not available on } \mathrm{HT} 50 .\end{array}$} \\
\hline
\end{tabular}

We evaluated triggering response to determine the effort required to trigger the ventilator. We evaluated ventilator performance by measuring the lowest negative pressure, delay time, and rise time (Fig. 8). These measurements are important and better understood by respiratory therapists at the bedside than are traditional work-of-breathing measurements in $\mathrm{J} / \mathrm{L}$. The effort required for ventilator triggering is $10-20 \%$ of the breathing effort in pressuresupport ventilation. More sensitive breath-detection is associated with shorter delay time and fewer ineffective triggering efforts. ${ }^{6}$

At the weak effort there were no significant differences in triggering among the tested ventilators, but as we increased the inspiratory effort, the differences increased. At both PS settings, with the strong effort the HT50 was inferior to the Evita XL in lowest negative pressure and delay time, but was superior to the Evita XL in rise time. The HT50 is pressure-triggered and has a dual micro-

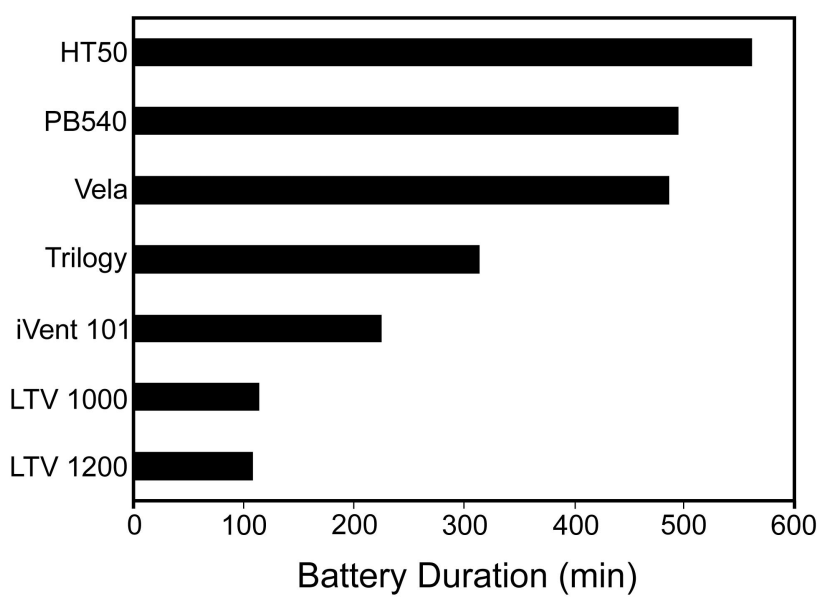

Fig. 7. Battery duration.

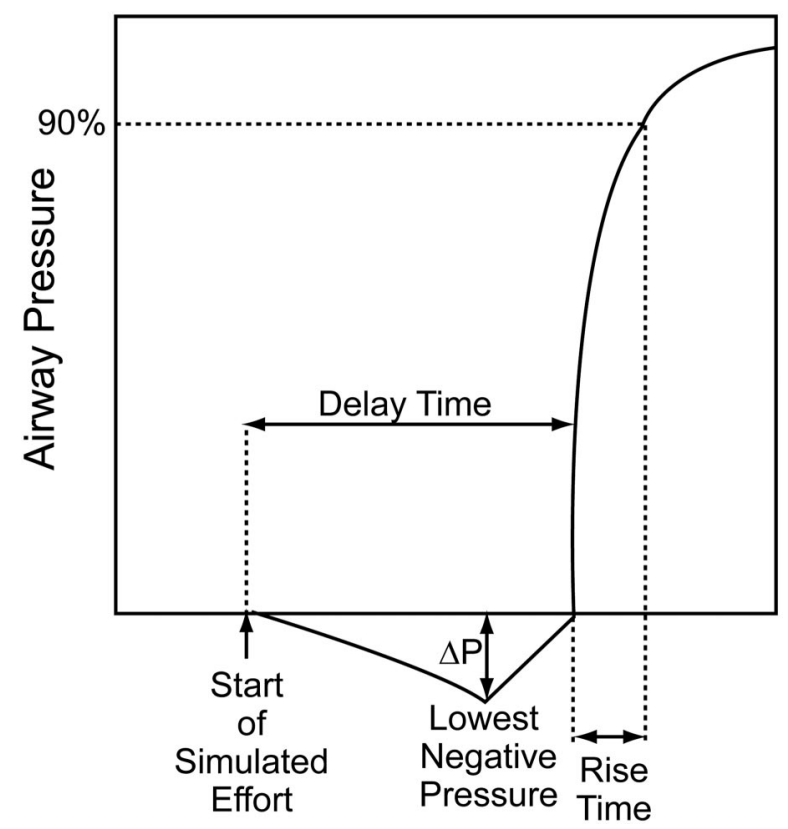

Fig. 8. Definitions of delay time, rise time, and lowest negative pressure during a pressure-support breath.

piston drive mechanism that might be slower to respond than the turbines in the other ventilators (see Table 1) but can produce high flow once initiated. Laboratory and clinical testing showed that flow-triggering imposes significantly less work of breathing than pressure-triggering during pressure-support ventilation. ${ }^{6}$

The rise time reflects how fast the ventilator pressurizes to $90 \%$ of the PS setting. In laboratory studies a lower rise time was associated with lower work of breathing and decreased patient discomfort. ${ }^{6-8}$ Previous studies have used various criteria to evaluate rise time. Several studies measured the time from beginning of inspiration to the time points $0.3,0.5$, and 1.0 second to determine the percentage of the set PS achieved at each point, $, 3,6,8$ or measured from 


\section{Bench Evaluation of 7 Home-Care Ventilators}

the lowest negative pressure to $90 \%$ of the PS setting. ${ }^{4} \mathrm{We}$ measured the time from baseline after triggering to $90 \%$ of the PS setting, to represent the ventilator's ability to pressurize after triggering. Shorter rise time equates to a lower overall inspiratory work of breathing. Although the HT50 was significantly inferior to the other ventilators in the lowest-negative-pressure and delay-time evaluations, the HT50 had the second-fastest rise time, which indicates its ability to produce a high flow after triggering. A possible explanation for the fact that the HT50 had the lowest negative pressure and longest delay time is that the HT50 offers only pressure-triggering. It is generally accepted that pressure-triggering requires more patient effort than flow-triggering and therefore produces a lower negative pressure and a longer delay time. ${ }^{8}$ In clinical practice the fastest rise time does not always result in the lowest work of breathing or patient comfort. This is important for interpretation of our work and that of others. Faster rise time does not necessarily imply superiority in clinical performance.

Delivered $\mathrm{V}_{\mathrm{T}}$ differed according to the ventilation settings and compliance and resistance combinations. At a respiratory rate of 30 breaths $/ \mathrm{min}$ and a $\mathrm{V}_{\mathrm{T}}$ of $400 \mathrm{~mL}$, all the ventilators delivered $V_{T}$ within the American Society for Testing and Materials standard. This can be attributed to the relatively normal respiratory rate and resistance settings. At a respiratory rate of 50 breaths $/ \mathrm{min}, \mathrm{a} \mathrm{V}_{\mathrm{T}}$ of 50 or $100 \mathrm{~mL}$, and the lower compliance and higher resistance settings, the accuracy of the Vela and the HT50 decreased. The Vela produced $\mathrm{V}_{\mathrm{T}}$ that were $>20 \%$ of the set volume at both $\mathrm{V}_{\mathrm{T}}$ settings. The HT50 produced $\mathrm{V}_{\mathrm{T}}$ of $>40 \%$ of set $\mathrm{V}_{\mathrm{T}}$ at the $100 \mathrm{~mL}$ setting. The $\mathrm{V}_{\mathrm{T}}$ differences with the Vela and HT50 can be attributed to air-trapping caused by the high respiratory rate and resistance settings, and exhalation-valve resistance; the flow waveforms showed the $\mathrm{V}_{\mathrm{T}}$ was not completely exhaled before the next breath was delivered. Additionally, on the HT50 the minimum $\mathrm{V}_{\mathrm{T}}$ setting is $100 \mathrm{~mL}$, so it could not be evaluated at a $\mathrm{V}_{\mathrm{T}}$ of $50 \mathrm{~mL}$. The minimum $\mathrm{V}_{\mathrm{T}}$ setting on the iVent 101 is $40 \mathrm{~mL}$, but we did not test that $\mathrm{V}_{\mathrm{T}}$ because the minimum $\mathrm{V}_{\mathrm{T}}$ setting on the remaining ventilators was $50 \mathrm{~mL}$.

Battery duration is important in the event of power outage. Emergency backup power is not typically available in the home, so it is imperative that a home-care ventilator have adequate battery duration. The loss of power in the aftermath of disasters such as hurricane Katrina highlights this point. ${ }^{9}$ All 7 tested ventilators had a battery duration in excess of $100 \mathrm{~min}$, and the HT50 had the longest battery duration: $561 \mathrm{~min}$.

Battery duration is affected by battery type and size, ventilation settings, and operating characteristics (see Table 1). For a given battery type, a larger battery provides longer battery duration. Historically, portable ventilators used lead/acid batteries because they are inexpensive, du- rable, and do not develop memory, but they are also heavy. In our study the lead/acid batteries provided both the longest and shortest battery durations. The lithium ion and nickel metal hydride batteries are smaller, lighter, have a higher energy density (power for a given size), and shorter charging time than lead/acid batteries. ${ }^{10}$ Lithium ion batteries are used in the ventilators that have variable-speed turbines. The HT50 has a secondary nickel metal hydride battery that provides up to $30 \mathrm{~min}$ of power after the lead/acid battery is depleted.

Turbine-driven ventilators typically have a shorter battery duration than piston-driven ventilators, ${ }^{11}$ as demonstrated by our results. This can be partially attributed to the nature of the turbine and the continuous bias flow, which facilitate triggering. A variable-speed turbine increases turbine speed during inspiration and decreases speed during exhalation, therefore using less energy than a constantspeed turbine. Only the LTV 1000 and LTV 1200 use a constant-speed turbine, and therefore have shorter battery duration. The HT50 had the longest battery duration because it has a lead/acid battery and secondary nickel metal hydride battery and a piston-driven pump that does not provide bias flow.

\section{Limitations}

We tested only one of each ventilator. We assume but cannot be certain that all ventilators of a certain model would perform similarly. All the tested ventilators were either received new from the manufacturer or had recent preventive maintenance. We used a lung model and a limited number of scenario conditions, which provided equal comparison of the ventilators, but our bench results cannot be presumed to translate to performance with patients.

\section{Conclusions}

Some of the ventilators we tested approached or exceeded the performance of the Evita XL ICU ventilator. There were significant differences between the ventilators. While some of the ventilators had much longer battery duration, others excelled in triggering, and others had more accurate respiratory rate and $\mathrm{V}_{\mathrm{T}}$. Clinicians must consider these differences when prescribing home-care ventilators.

\section{REFERENCES}

1. Huang TT, Peng JM. Role adaptation of family caregivers for ventilator-dependent patients: transition from respiratory care ward to home. J Clin Nurs 2010;19(11-12):1686-1694.

2. Boroughs, DS, Dougherty J. A multidisciplinary approach to the care of the ventilator-dependent child at home. Home Healthcare Nurse 2010;28(10):24-28.

3. Battisti A, Tassaux D, Janssens JP, Michotte JB, Jaber S, Jolliet P. Performance characteristics of 10 home mechanical ventilators in 


\section{Bench Evaluation of 7 Home-Care Ventilators}

pressure-support mode: a comparative bench study. Chest 2005; 127(5):1784-1792.

4. Branson RD, Davis KD. Work of breathing imposed by five ventilators used for long-term support: the effects of PEEP and simulated patient demand. Respir Care 1995;40(12):1270-1278.

5. Ferreira, JC, Chipman DW, Kacmarek RM. Trigger performance of mid-level ICU mechanical ventilators during assisted ventilation: a bench study. Intensive Care Med 2008;34(4):1669-1675.

6. Richard JC, Carlucci A, Breton L, Langlais N, Jaber S, Maggiore S, et al. Bench testing of pressure support ventilation with three different generations of ventilators. Intensive Care Med 2002;28(5):1049-1057.

7. MacIntyre NR, Gropper $\mathrm{C}$, Westfall $\mathrm{T}$. Combining pressure-limiting and volume-cycling features in a patient-interactive mechanical breath. Crit Care Med 1994;22(2):353-357.
8. Thille AW, Lyazidi A, Richard JC, Galia F, Brochard L. A bench study of intensive-care-unit ventilators: new versus old and turbinebased versus compressed gas-based ventilators. Intensive Care Med 2009;35(4):1368-1376.

9. Barton AC, Tuttle-Newhall JE, Szalados JE. Portable power supply for continuous mechanical ventilation during intrahospital transport of critically ill patients with ARDS. Chest 1997;112(2): 560-563.

10. Blakeman T, Robinson B, Branson R. Battery performance of 4 intensive care ventilator models. Respir Care 2010;55(3):317-321.

11. Campbell RS, Johannigman JA, Branson RD, Austin PN, Matacia G, Banks GR. Battery duration of portable ventilators: effects of control variable, positive end-expiratory pressure, and inspired oxygen. Respir Care 2002;47(10):1173-1183. 